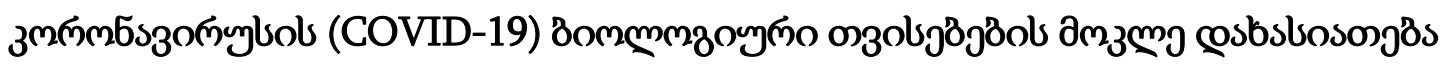

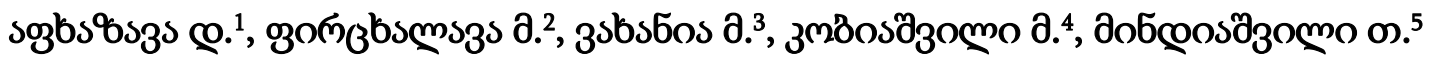

бmosdo 2.6

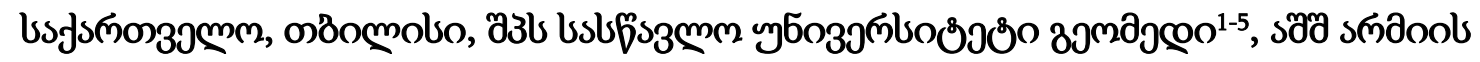

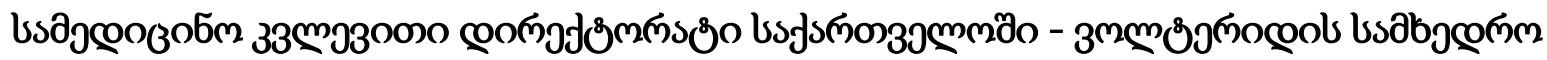

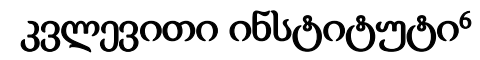

\title{
Øjlssзsmo
}

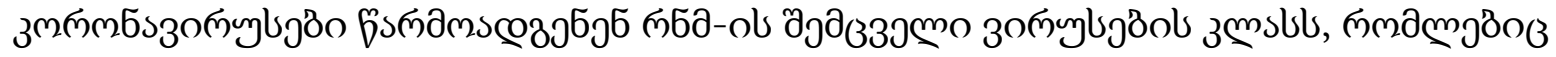

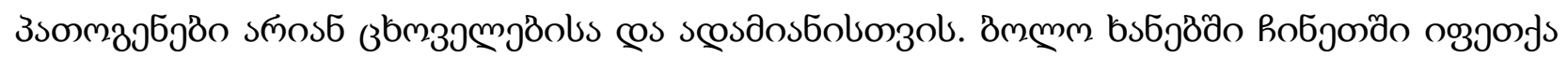

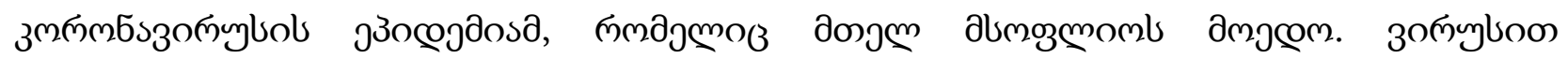

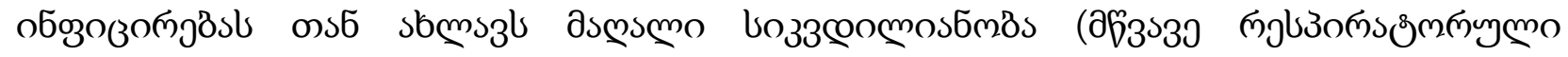

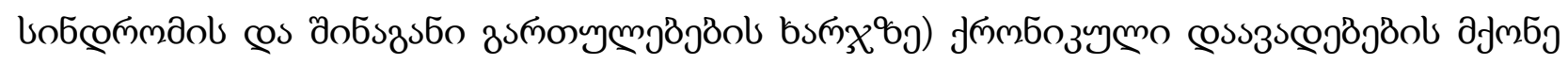
3sзолб

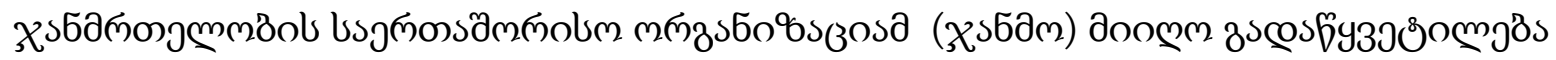

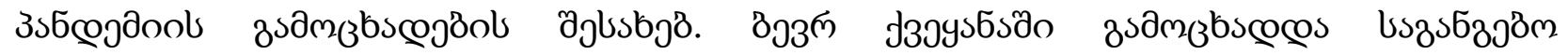

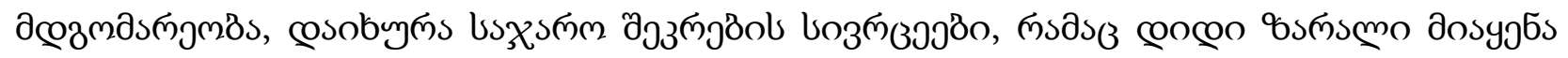

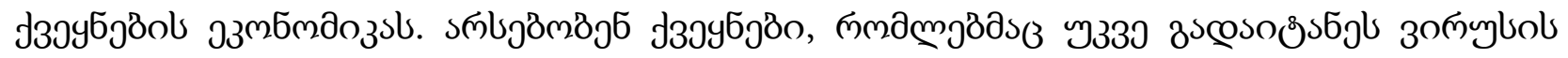

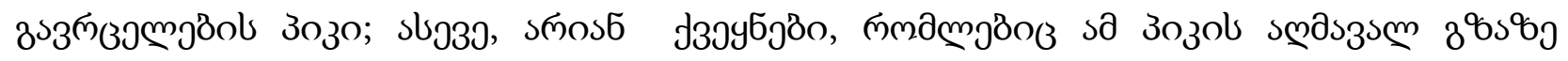

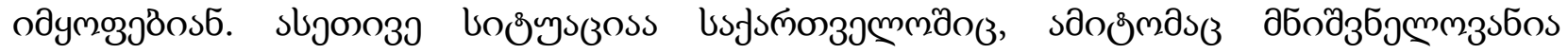

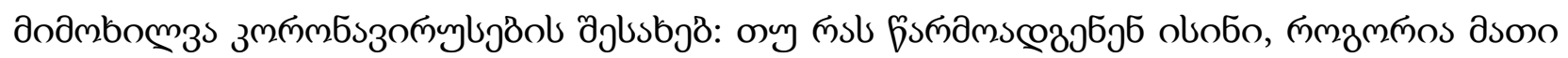

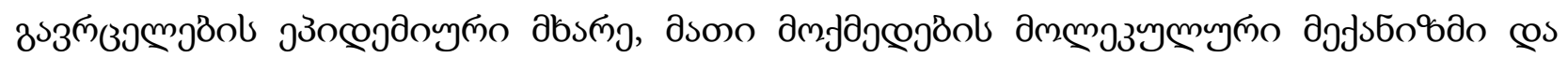

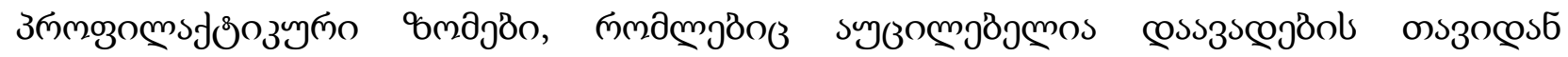
slusomgingsce.

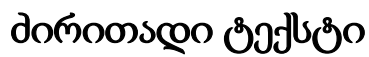

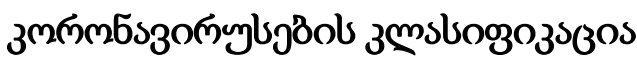

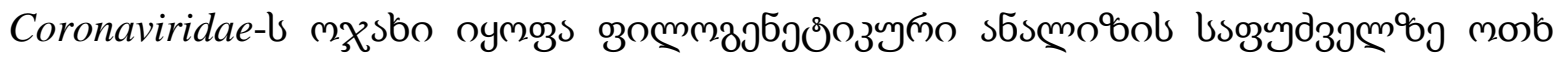

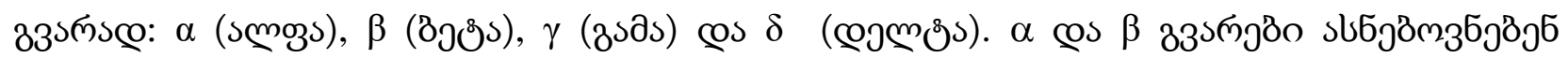

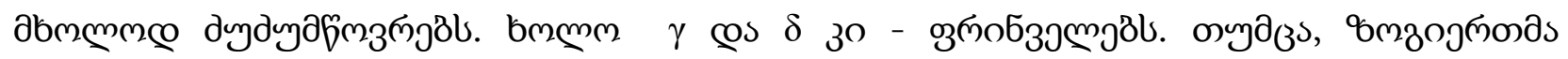

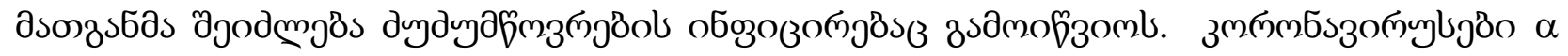

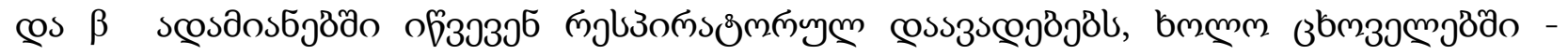

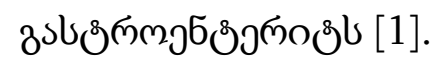

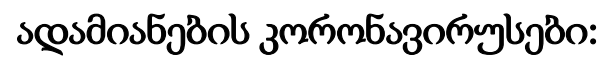

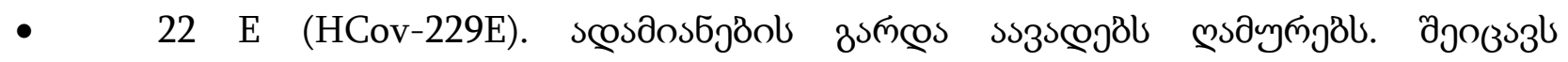

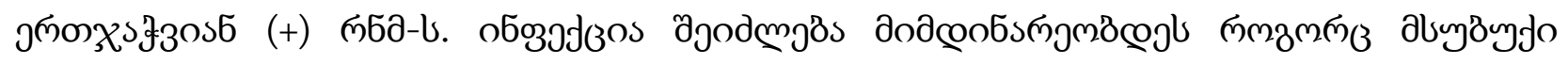

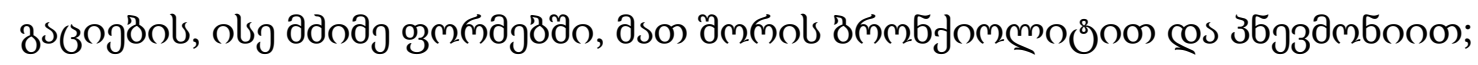

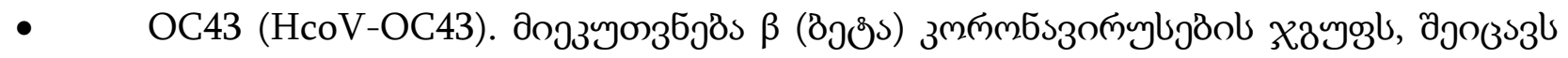

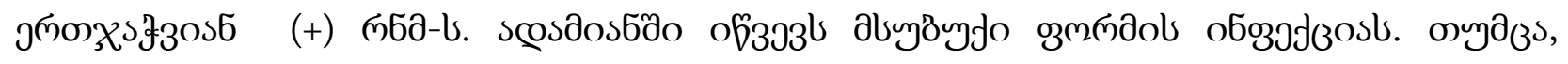




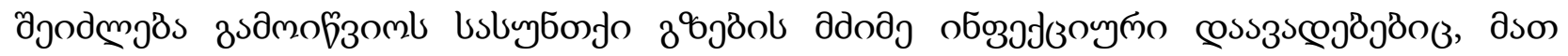

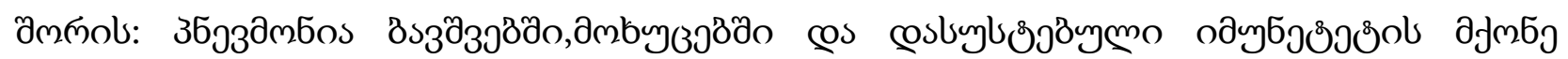
उомुวठо;

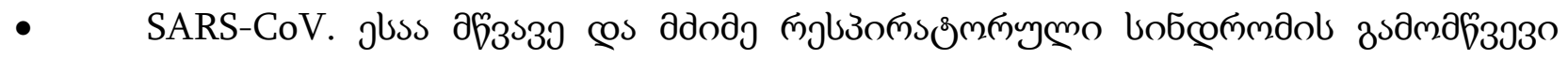

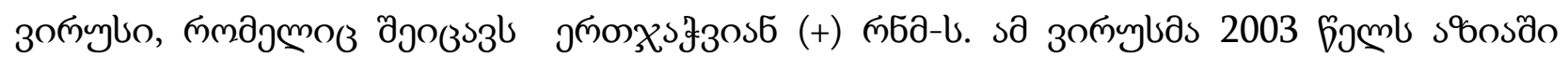

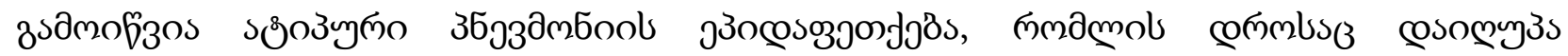
cosszscö̈ymons 9\%;

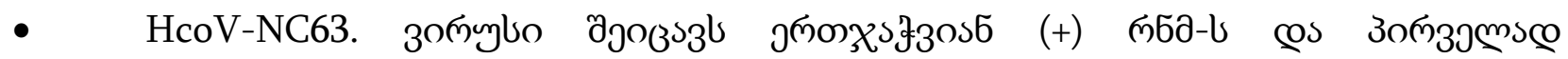

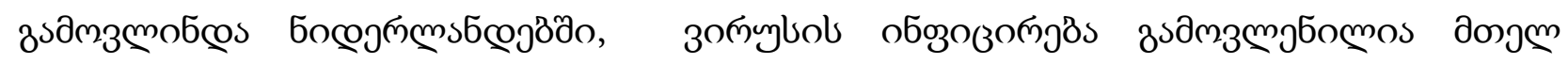

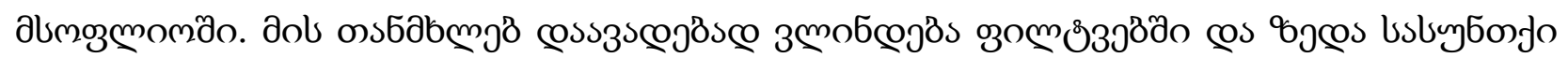

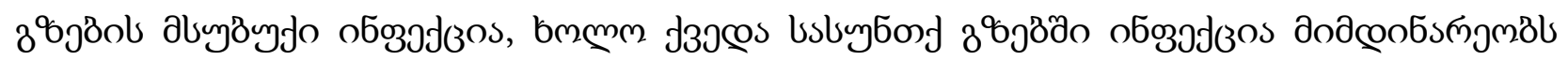
адодэю;

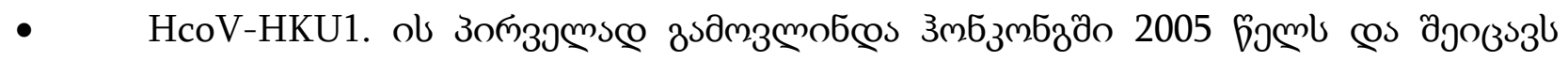

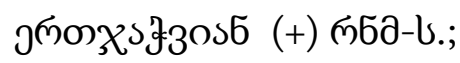

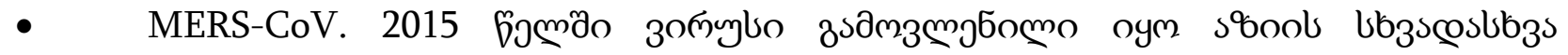

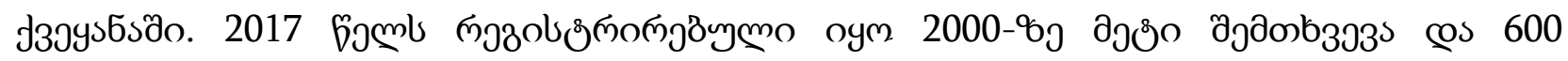

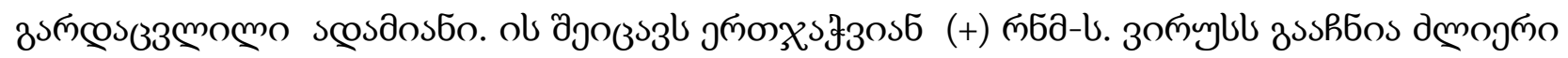

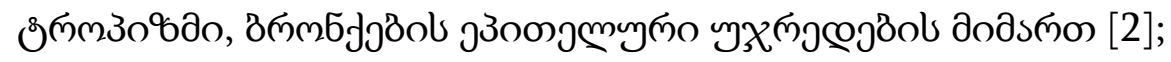

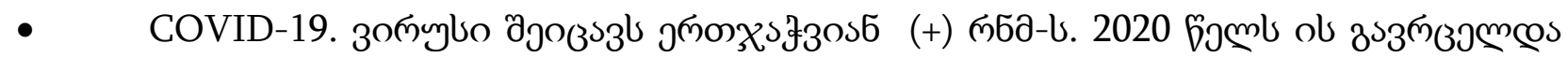

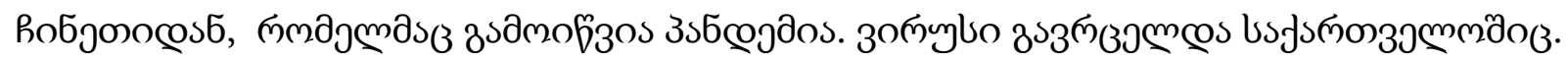

\section{COVID-19-ol jзосдаомеммдоs}

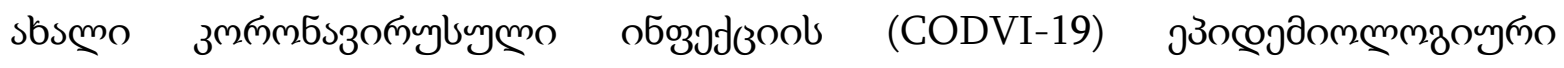

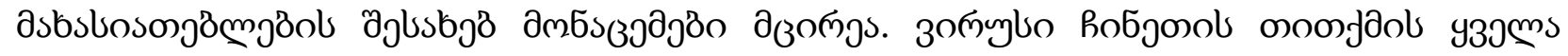

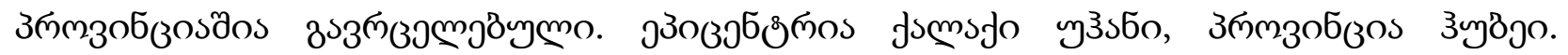

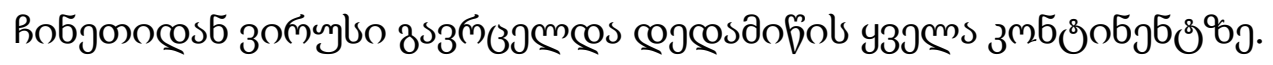

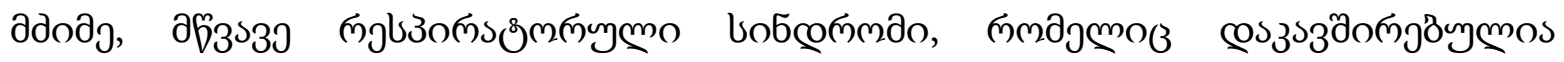

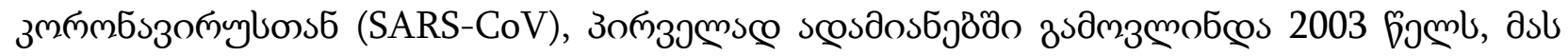

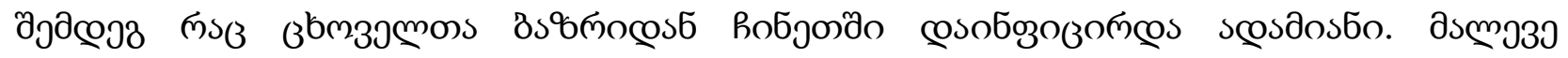

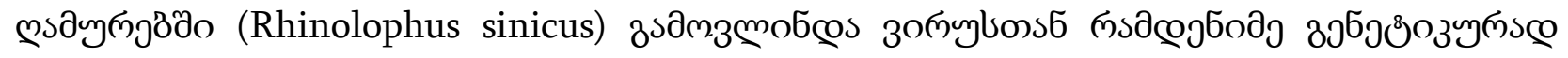

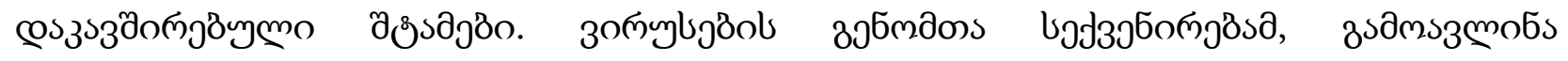

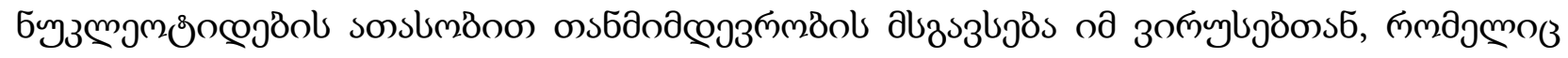

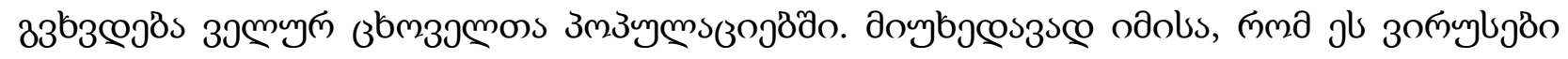

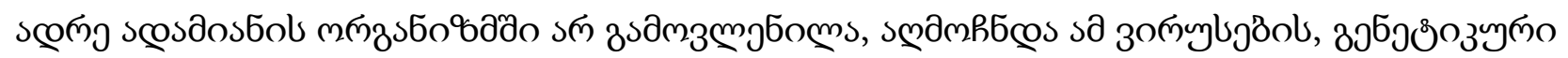

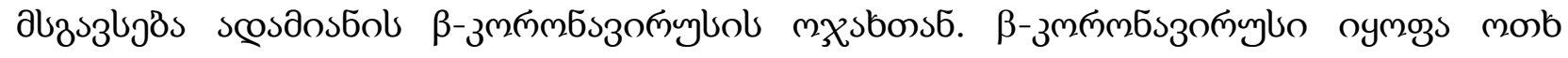

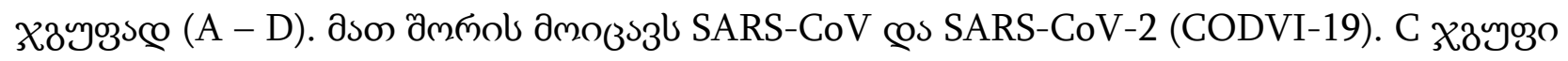

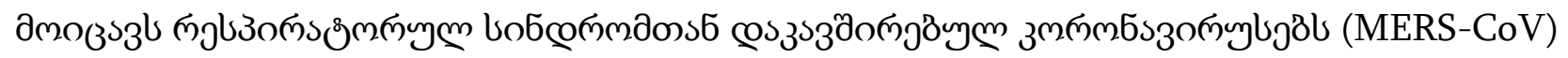
$[3 ; 4]$.

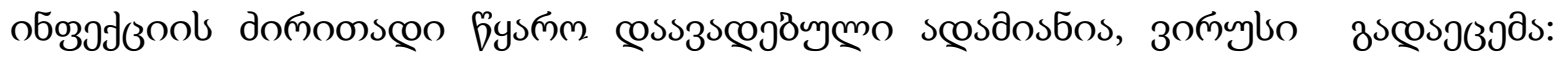

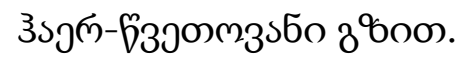




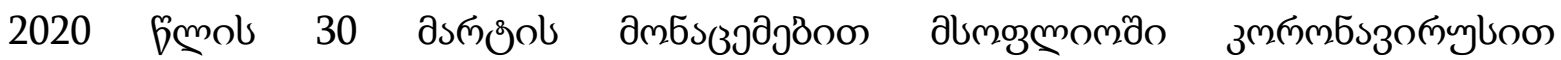

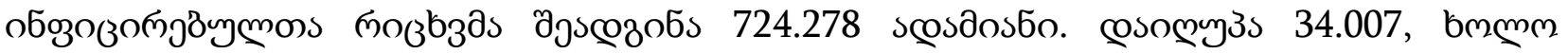

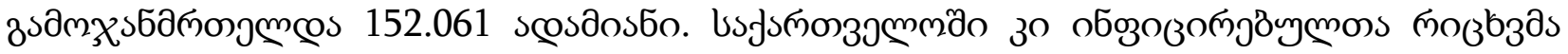

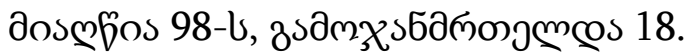

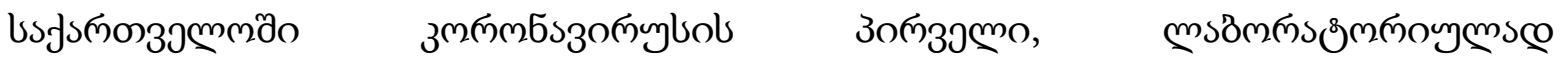

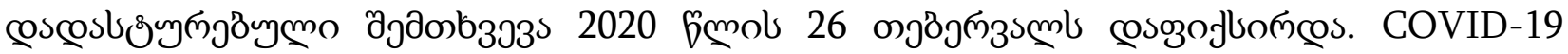

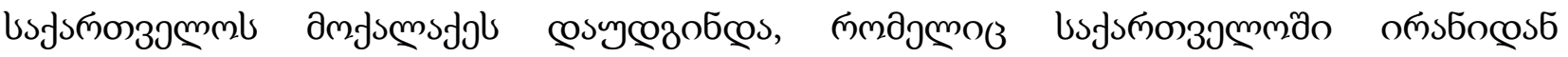

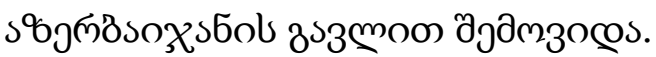

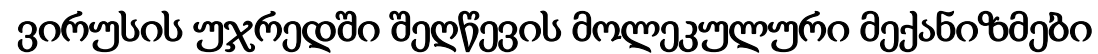

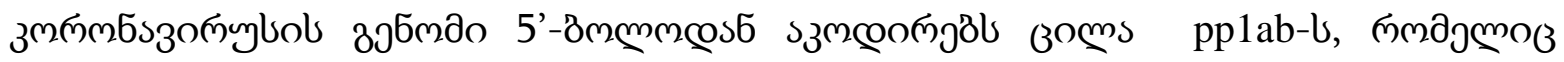

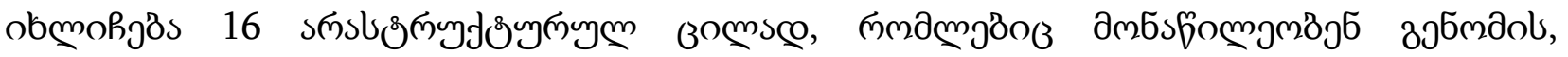

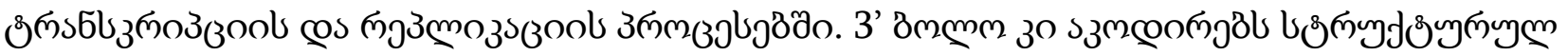
उomjol [5].

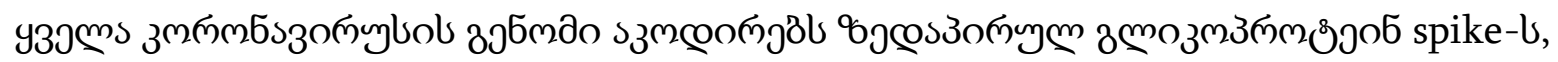

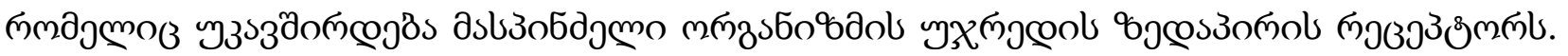

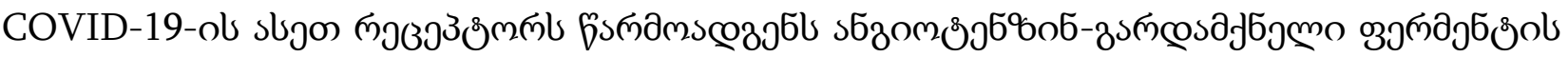

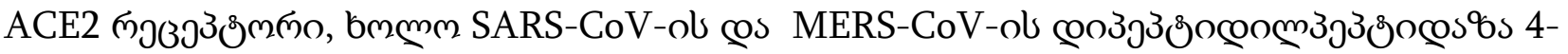

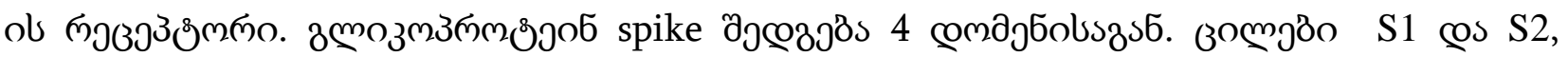

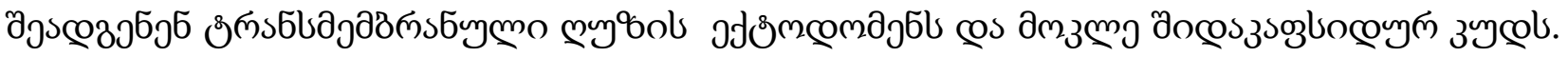

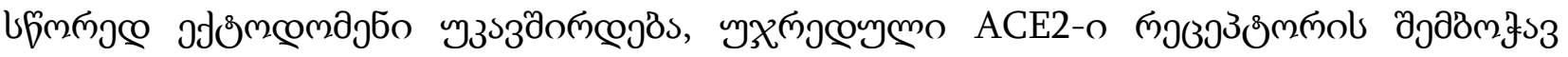

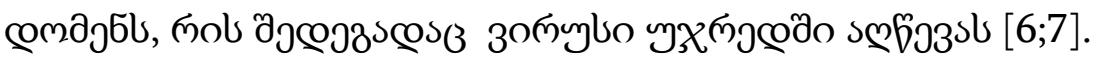

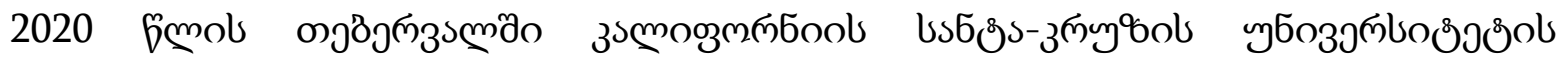

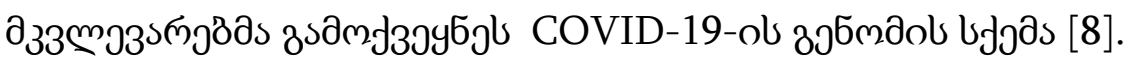

\section{IVDC-HB-01/2019 ( 29.8kb)}

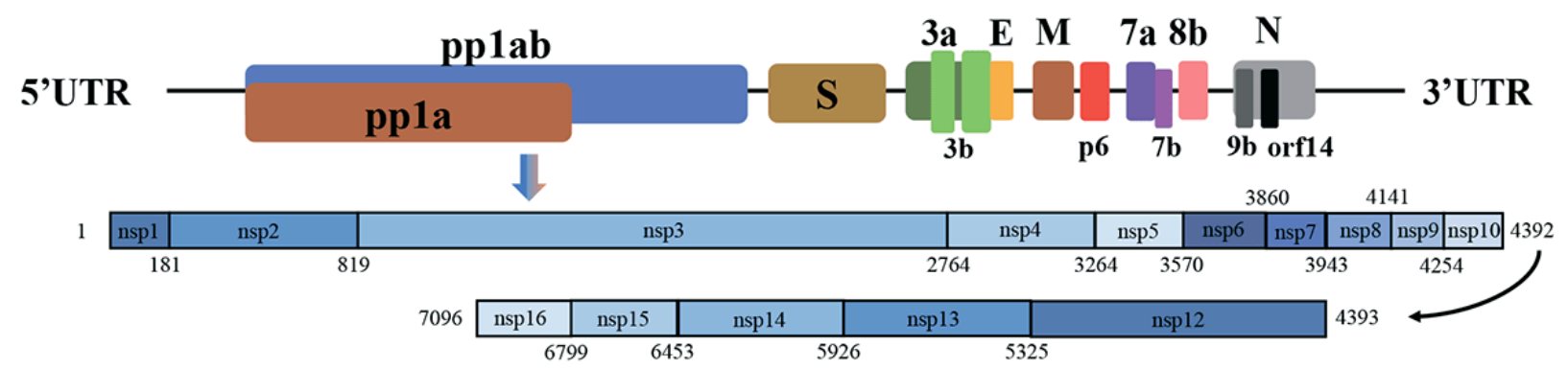

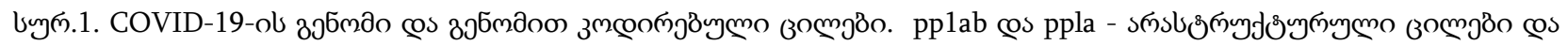

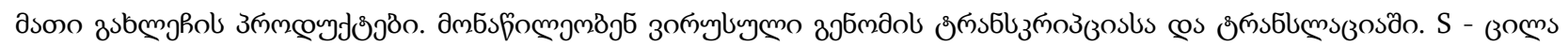

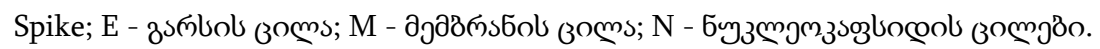

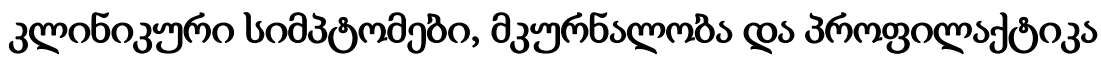

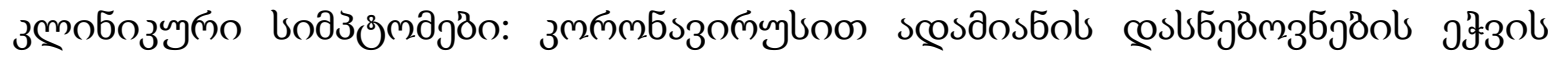

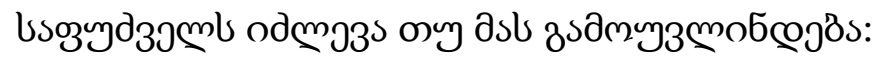

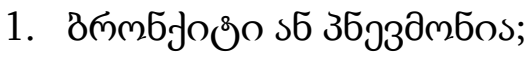




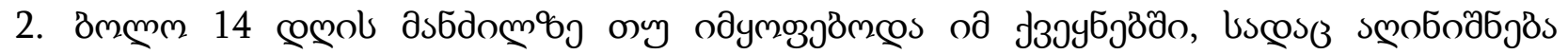

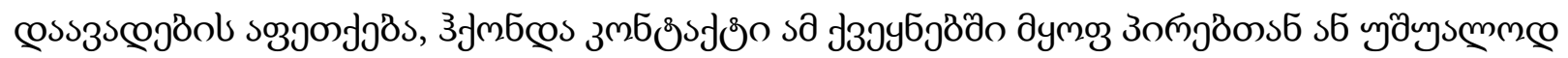

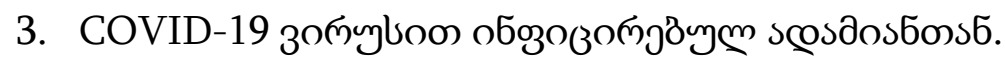

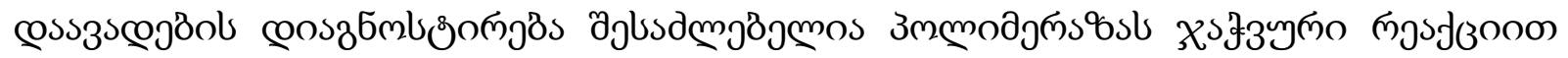

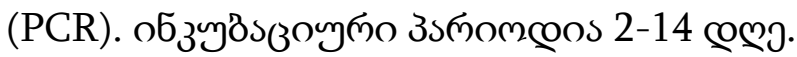

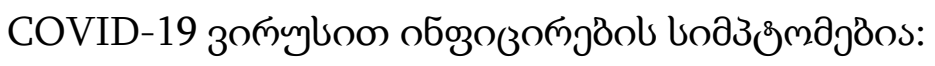

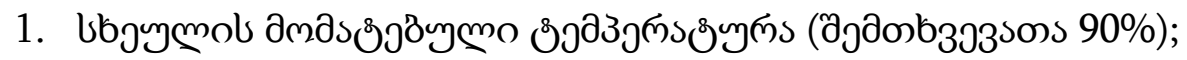

2. b39ms (80\%);

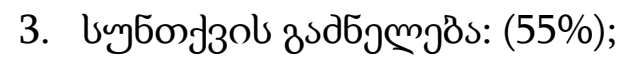

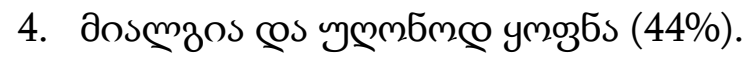

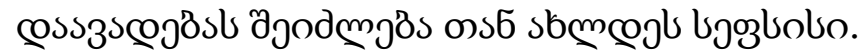

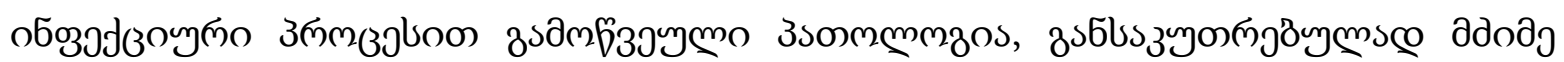

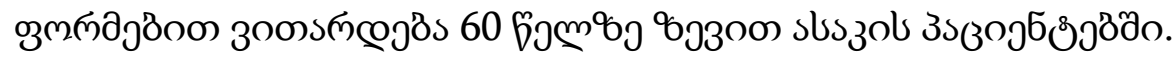

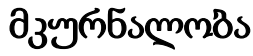

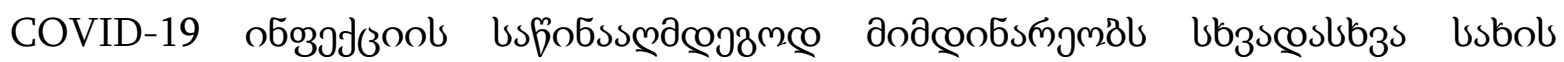

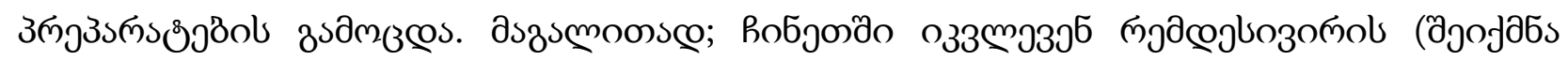

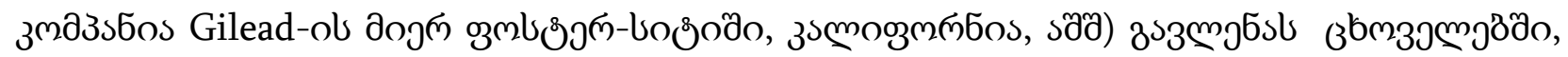

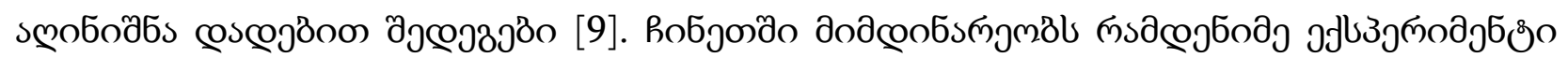

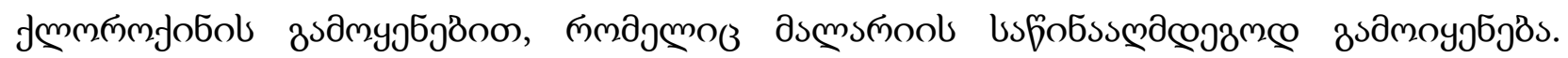

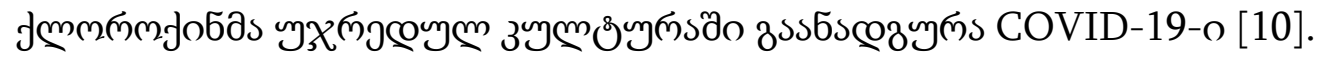

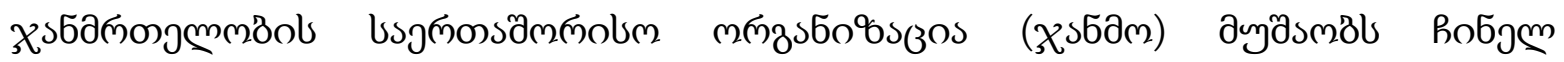

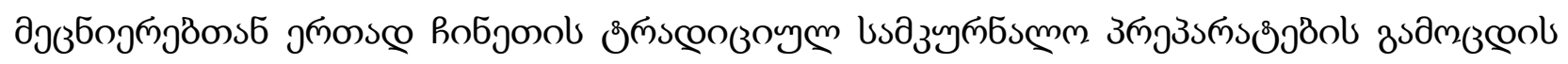

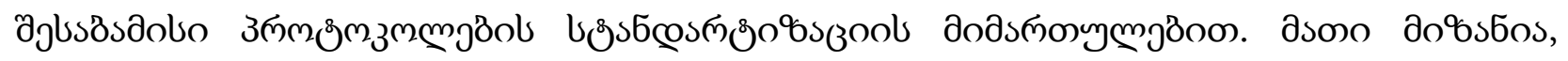

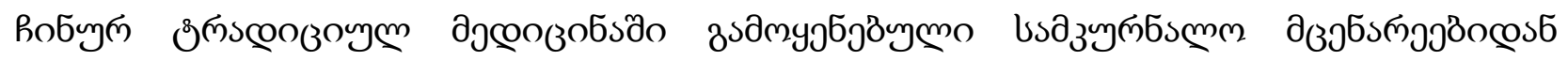

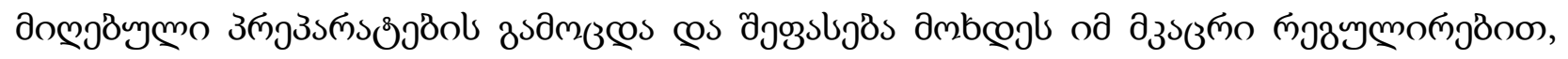

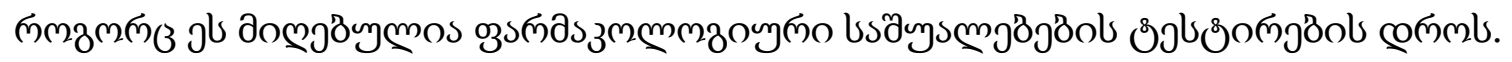

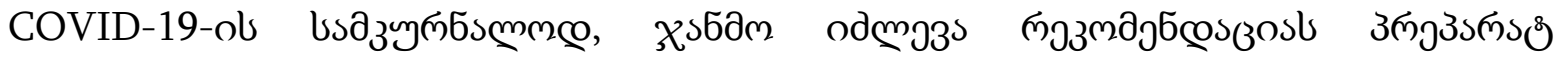

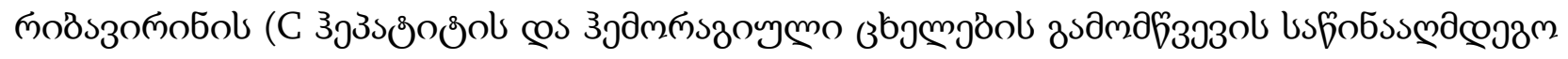

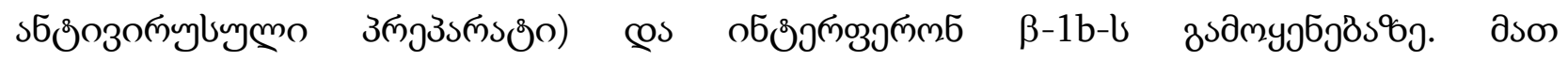

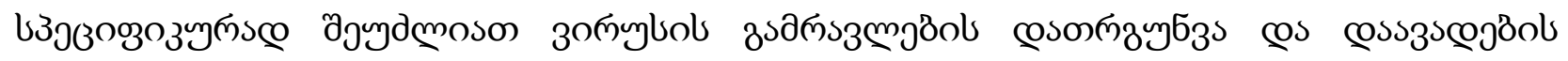

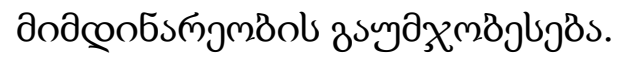

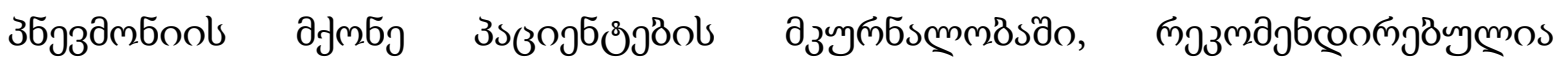

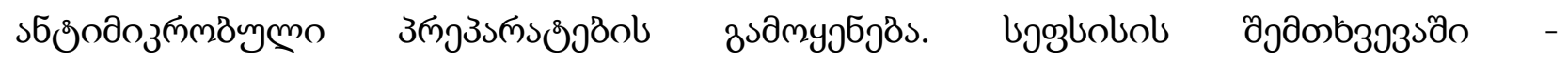

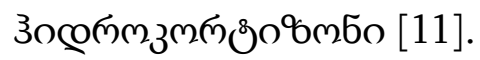

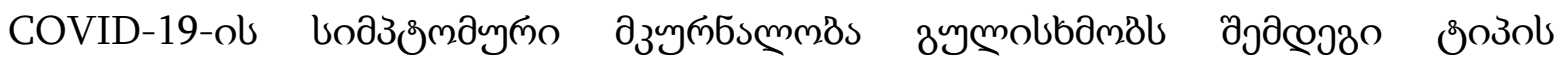

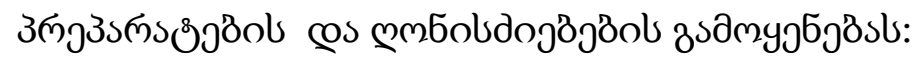

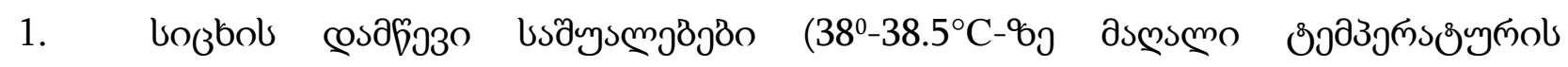

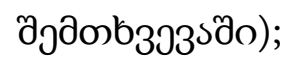

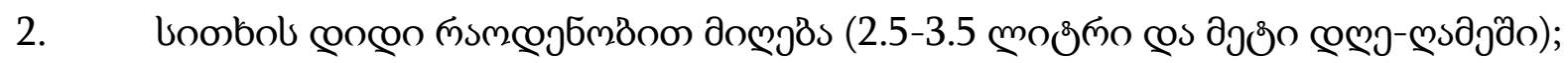




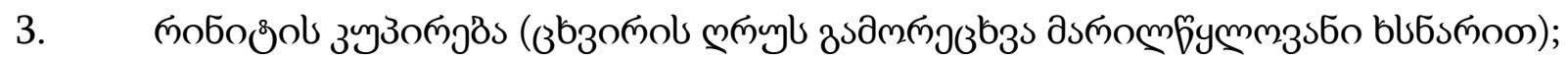

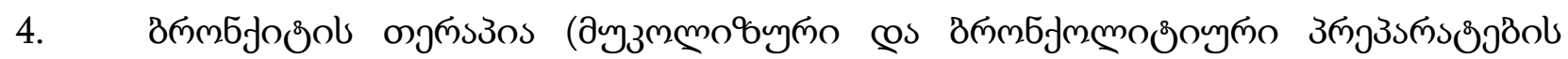

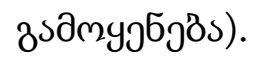

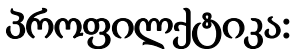

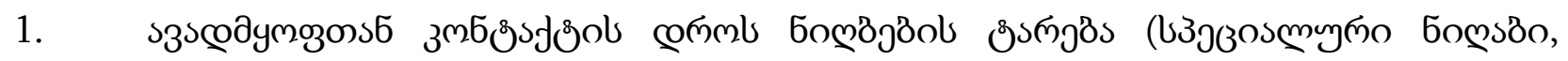

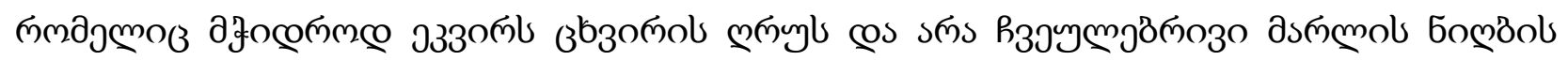
зsдmyjбjos);

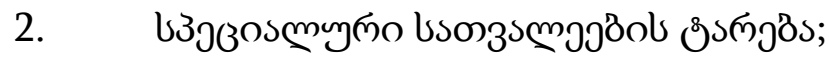

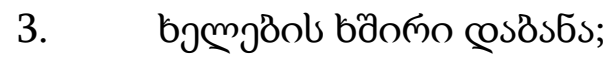

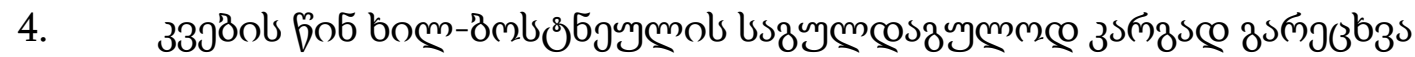

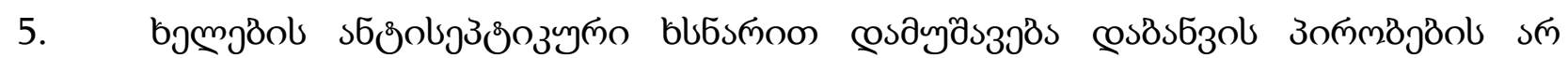
jmbolsbl[12].

\section{cost336s}

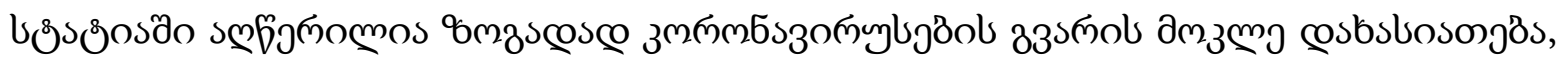

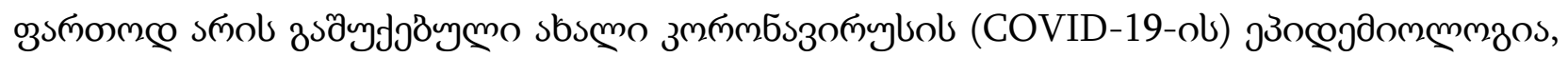

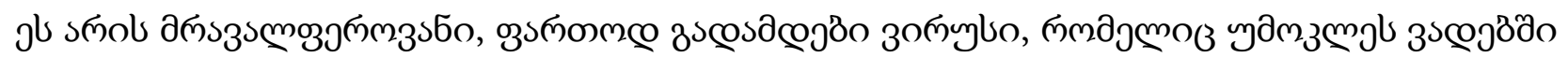

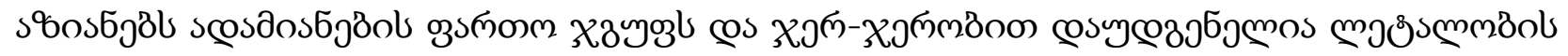

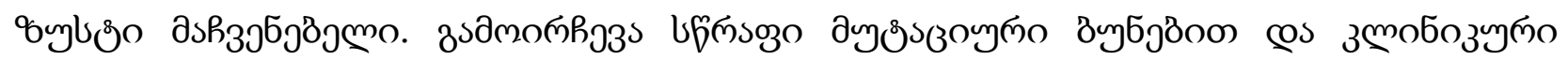

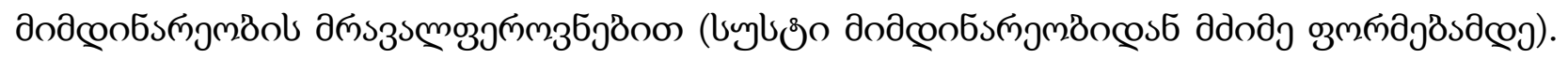

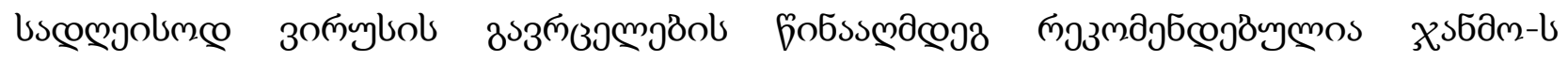

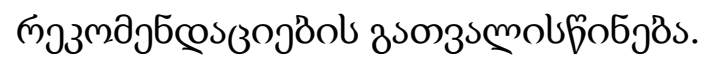

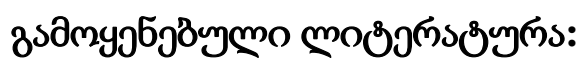

1. Jie Cui, Fang Li, Zheng-Li Shi. (2019). Origin and evolution of pathogenic coronaviruses. Nat Rev Microbiol. 17, 181-192;

2. $\quad$ "Virus Taxonomy: 2018b Release". International Committee on Taxonomy of Viruses (ICTV). March 2019. Archived from the original on 2018-03-04. Retrieved 2020-01-24.

3. Ge, X. Y. et al. Isolation and characterization of a bat SARS-like coronavirus that uses the ACE2 receptor. Nature 503, 535-538 (2013).

4. $\mathrm{Hu}, \mathrm{B}$. et al. Discovery of a rich gene pool of bat SARS-related coronaviruses provides new insights into the origin of SARS coronavirus. PLoS Pathog. 13, e1006698 (2017).

5. Stephen N.J. Korsman, Gert U. van Zyl, Louise Nutt, Monique I. Andersson, Wolfgang Preiser. (2012). Human coronaviruses. Virology. 94-95;

6. Raj, V. S. et al. Dipeptidyl peptidase 4 is a functional receptor for the emerging human coronavirus-EMC. Nature 495, 251-254 (2013).

7. $\mathrm{Li}, \mathrm{W}$. et al. Angiotensin-converting enzyme 2 is a functional receptor for the SARS coronavirus. Nature 426, 450-454 (2003). 
8. Genome Composition and Divergence of the Novel Coronavirus (2019-nCoV) Originating in China.

9. Guangdi, L. \& De Clercq. Therapeuticoptions for the 2019 novel coronavirus (2019-nCoV) E. Nature Rev. Drug Discov. http://doi.org/10.1038/d41573-020-00016-0 (2020).

10. Manli Wang, Ruiyuan Cao, Leike Zhang, Xinglou Yang, Jia Liu, Mingyue Xu, Zhengli Shi, Zhihong $\mathrm{Hu}$, Wu Zhong, Gengfu Xiao. Remdesivir and chloroquine effectively inhibit the recently emerged novel coronavirus (2019-nCoV) in vitro.

11. Novel Coronavirus (2019-nCoV) situation reports. WHO.

12. Esfandiari S. (2020). Here are the symptoms of the Wuhan coronavirus, according to a new CDC warning. ScienceAlert.

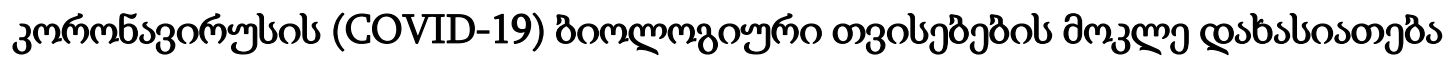

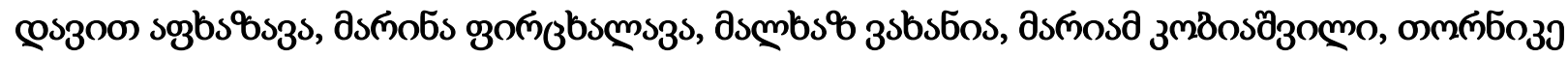

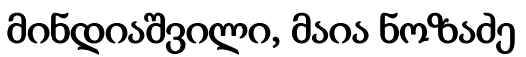

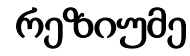

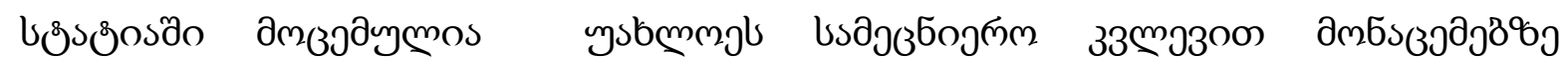

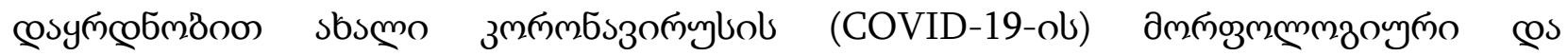

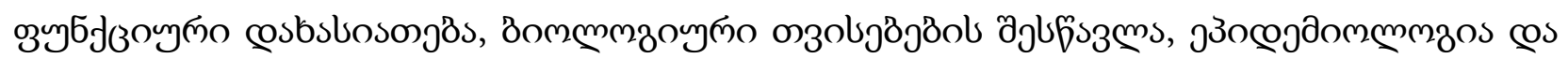

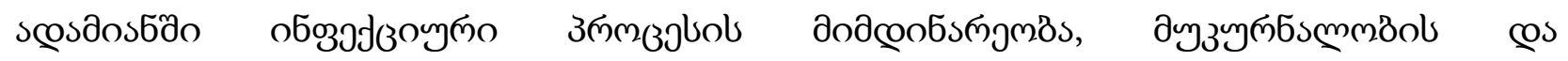

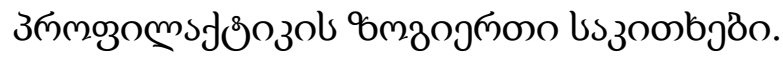

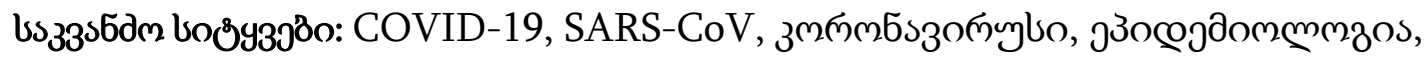

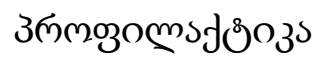

Brief description of the biological properties of coronavirus (COVID-19)

David Aphkhazava, Marina Pirtskhalava, Malkhaz Vakhania, Mariam Kobiashvili, Tornike Mindiashvili, Maia Nozadze

Summary

The article provides morphological and functional characterization of the new coronavirus (COVID-19) based on the latest scientific research data, study of biological properties, epidemiology and the course of the infectious process in humans, some issues of treatment and prevention.

Keywords: COVID-19, SARS-CoV, Coronavirus, Epidemiology, Prevention 
Краткое описание биологических свойств коронавируса (COVID-19)

Давид Абхазава, Марина Пирцхалава, Малхаз Вахания, Мариам Кобиашвили, Торнике Миндиашвили, Майя Нозадзе

Резюме

В статье приведена морфофункциональная характеристика нового коронавируса (COVID-19) на основе новейших научных данных, изучения биологических свойств, эпидемиологии и хода инфекционного процесса у человека, некоторых вопросов лечения и профилактики.

Ключевые слова: COVID-19, SARS-CoV, коронавирус, эпидемиология, профилактика. 